\title{
Weight Loss Maintenance: An Agenda for Health Psychology
}

\author{
Falko F Sniehotta, Newcastle University
}

Sharon A Simpson, University of Cardiff

Colin J Greaves, University of Exeter

In press: British Journal of Health Psychology

\section{Correspondence}

Dr Falko Sniehotta

Centre for Translational Research in Public Health

Institute of Health and Society

Medical Faculty

Newcastle University

Baddiley-Clark Building

Richardson Road

NE2 4AX

\section{Acknowledgements:}

Falko F. Sniehotta is funded by Fuse, the Centre for Translational Research in Public Health, a UKCRC Public Health Research Centre of Excellence. Funding for Fuse from the British Heart Foundation, Cancer Research UK, Economic and Social Research Council, Medical Research Council, and the National Institute for Health Research, under the auspices of the UK Clinical Research Collaboration, is gratefully acknowledged. Colin Greaves' time is supported by the National Institute for Health Research (Career Development Fellowship, CDF-2012-05-259). The views expressed in this publication are those of the authors and not necessarily those of the funders. 
There is an urgent need for cost-effective interventions to promote weight loss maintenance (WLM) and this presents an important opportunity for our discipline. Firstly, health psychologists can make a contribution to solving this important public health issue. With their knowledge of theory, behaviour change techniques, process evaluation and intervention development tools, like intervention mapping, (Bartholemew et al., 2011) and causal modelling (Hardeman et al., 2005), health psychologists have a key role to play in the development of effective WLM interventions as part of a multi-disciplinary approach. Secondly, conducting research into WLM could lead to significant advances in theory and in methods for intervention development and evaluation. This editorial will highlight some of the key challenges and opportunities associated with interventions, theory and methods relevant for maintenance of weight loss and behaviour change.

Obesity is the greatest cause of preventable morbidity and mortality in the developed world. By 2050, if obesity continues to rise the combined cost to the NHS and society has been estimated to be almost $£ 50$ billion per annum (Butland et al, 2007). We know that losing weight (WL) reduces morbidity and mortality (Penn et al., 2013) and that behavioural interventions focusing on changes in eating and physical activity behaviour are effective in inducing clinically significant WL (Avenell et al. 2004; Dombrowski et al., 2010). Effective WL programmes are available (Jolly et al., 2011). However, people usually regain a third of their WL within a year and the rest within 3-5 years (Avenell et al., 2004; Dombrowski et al., 2010). Preventing weight regain in the long term after successful WL is vital, as the clinical and economic benefits of WL interventions depend strongly on how long the effects can be maintained.

\section{Interventions}


Reviews of the intervention literature have shown that it is possible to slow the regain process through extended interventions (Middleton et al., 2011; Simpson et al., 2012). However,

overall, success is somewhat modest. A recent systematic review found that behavioural interventions focusing on both, dietary intake and physical activity resulted on average in a reduction of weight regain over one year of $1.56 \mathrm{~kg}$ compared to controls (Dombrowski et al., 2014). The majority of interventions evaluated to date have not been explicitly influenced by psychological theory. WLM interventions often use similar intervention techniques as WL interventions such as self-regulation techniques and social support. There is some support for these-for instance there is growing evidence suggesting that daily self-weighing is effective (Madigan et al., in press; Larose et al., 2014). Another potentially useful self-regulation based intervention is the 5-step problem solving approach (Perri et al., 2001).

However, there is no conclusive evidence about the most effective intensity (frequency, duration), delivery mode, timing or behaviour change techniques for supporting WLM. It may also be worth exploring beyond individual interventions Additional investment in policy and environmental (e.g., transport, workplace, food environment) interventions may help to support sustained public health impact (Chokshi et al., 2012).

\section{Theory}

While there is some encouraging evidence, many key questions about WLM interventions remain unanswered. However, as we suggest below, the development or application of behaviour change theories could help to advance the field.

The behavioural analysis of WLM is complex. Food intake and physical activity are affected by a complex system of interacting societal, policy, community, social, economic and individual factors (Butland et al., 2007). Motivations and barriers to change vary widely 
between individuals. After initial WL, many obese individuals will still carry considerable excess weight. Hence, motivations to lose more weight may overlap or even conflict with the behaviours needed to maintain the initial WL In cases where WL is achieved through unsustainable means such as very low calorie diets, the transition from WL to WLM will often imply a further behavioural change. Little is known about whether the factors motivating initial WL behaviours and WLM behaviours are similar. We also know very little about how unhealthy relationships with food expire and how newly adopted behavioural patterns become habitual. Unravelling the complex relationships between behaviours, motivations, emotions, social influences and other determinants and their dynamic interplay over long periods of time is a significant theoretical challenge. However this could inform the development of interventions that are specific to the maintenance of diet and physical activity behaviours, as well as informing more general theories of behavioural maintenance.

The majority of theories of behaviour and behaviour change do not offer explicit explanations for maintenance. For the majority of theories explanations for an initial performance of a new behaviour are the same as for sustained action. Most social cognitive theories assume that exposure to behaviour feeds back into cognitions so that the same cognitions are explaining behaviour but that their content/level may change with experience, for example, people may become less motivated to work out when the physical results falls short of expectations.

Other theories suggest that the relative importance of behavioural determinants may change from initial uptake to sustained action. For example, according to self-determination theory, behaviour may be initiated based on extrinsic motivation, but is more likely to be sustained based on intrinsic motivation (Deci \& Ryan, 2000). Rothman (2000) suggests that while positive expectations of future outcomes motivate behavioural uptake, it is the ongoing 
perceived satisfaction with such outcomes which provides the sustained reinforcement needed to maintain the new behaviour.

The social cognitive account does not take into consideration that many behaviours are conducted without active deliberation, based on habits or impulses, i.e., learned behavioural responses to cues. Dual process models (e.g., Strack \& Deutsch, 2004) hypothesise that behaviour is guided by two parallel processes, a reflective process based on beliefs about the behaviour and its consequences and an impulsive process, based on learned automated responses. One route to the maintenance of behaviour change may therefore involve effortful self-regulation to override learned and automated responses. However, as impulsive responding requires fewer cognitive resources, it is hypothesised that attempts to override the habitual response will deplete the actor's self-regulatory resources (Hagger et al., 2010). Another route to inhibiting unhealthy impulses might be to 'extinguish' the habit using operant conditioning methods. A conceptually different approach is offered by Marlatt's Relapse Prevention Theory (Marlatt \& George, 1994), which theorises how a single lapse to previous patterns of behaviour may develop into a full relapse through a downward spiral of dysfunctional cognitions and negative emotions.

The relationship between psychological and non-psychological determinants of energy balance behaviours (such as environment, financial circumstances, food availability) is also insufficiently elaborated in contemporary theories. Epiphaniou and Ogden (2010) suggest that successful WLM may be the result of Life events (e.g., doctor's advice to lose weight) combined with sustaining conditions (e.g., reduced choices over lifestyle behaviours). Furthermore, most behavioural theories focus on a single behaviour and exclude other competing goals, commitments and activities which may affect the priority and/or resources given to the target behaviour (Presseau et al., 2010). 
It may be that some theories or intervention processes that have been successful in supporting WL are also applicable to WLM. However, a number of potentially relevant theoretical approaches have not yet been implemented in high quality randomised controlled trials of WLM, so there is scope for innovation. For example, current interventions have mainly exploited cognitive self-regulation processes such as goal-setting and self-monitoring (e.g., Wing et al., 2006). In contrast, participants trying to lose weight often identify emotional processes (eating as mood-regulation; impulse control) as being most relevant (Byrne et al., 2003). While dual process models incorporate such factors, they have not been regularly targeted in previous WLM interventions (Dombrowski et al., 2014).

Finally, empirical studies are needed to validate the change processes suggested by theory and identify which processes can be successfully manipulated to achieve long term WLM. The above is only a partial exploration of the field. Hence, a more comprehensive review of social and behavioural theories of WLM would help establish which theoretical hypotheses and explanations have been applied in empirical research and to identify gaps for further research.

\section{Methodological considerations}

One key challenge in this field is to develop methods that will help us to better understand the processes of WLM and thereby inform theoretical development. Maintenance may be strongly determined by temporal and contextual factors and research designs need to be sensitive to behavioural determinants which may vary dynamically over time. For example, in observational studies ecologic momentary assessment (using portable devices, mobile phones, wirelessly connected weight scales etc.) would allow the hypothesised determinants 
and outcomes to be observed in parallel and sequentially over time. Likewise, most qualitative studies about WLM are cross-sectional and retrospective, and more research is needed to track changes in individuals' thought processes and behaviours throughout the process of forming (or failing to form) new habits.

Interactions between the initial method of WL and maintenance interventions present another specific methodological challenge (i.e., the best maintenance method might depend on the initial method used for losing weight). Sequential research designs which randomise people to different initial WL regimes followed by randomisation to different maintenance regimes, may help to isolate effects for WL and WLM, as well as to identify potential interactions. Full or fractional factorial designs may be particularly promising in building, optimising and evaluating these interventions (Collins et al., 2009).

There are also methodological challenges in handling attrition as intention to treat methods may under-estimate effect size, whereas completer-only analyses are likely to over-estimate effects. More sophisticated methods for dealing with missing data are available, but need to be used with caution, including complier average causal effect (CACE) analyses and multiple imputation methods (Jo et al., 2008).

\section{Conclusion}

Research into WLM is still in its infancy. Psychological methods and theories may improve our understanding of maintenance, but work is needed to translate theoretical ideas into interventions, to test theory-based hypotheses, and to design research in ways that will help us to understand and modify the process of weight regain. We need to build the science through cycles of theory, methodology and trial evidence and we need to do it in a way that can provide rapid rollout of ideas into practice where workable solutions to the obesity epidemic are desperately needed. 


\section{References}

Avenell, A., Broom, J., Brown, T.J., Poobalan, A., Aucott, L., Stearns, S.C., Smith, W.C., Jung, R.T., Campbell, M.K. \& Grant, A.M. (2004). Systematic review of the long-term effects and economic consequences of treatments for obesity and implications for health improvement. Health Technology Assessment, 8(21), 1-182.

Bartholomew, L.K., Parcel, G.S., Kok, G., Gottlieb, N.H., \& Fernandez, M.E. (2011). Planning health promotion programs. An intervention mapping approach. (3rd ed.). San Francisco: Wiley.

Butland, B., Jebb, S., Kopelman P., McPherson, K., Thomas, S., Mardell, J. \& Parry, V. (2007). Tackling obesities: future choices - project report (2nd Ed). UK Government Office for Science.

Byrne, S., Cooper, Z. \& Fairburn, C. (2003). Weight maintenance and relapse in obesity: a qualitative study. International Journal of Obesity, 27, 955-962.

Chokshi, D.A., \& Farley, T.A. (2012). The Cost-Effectiveness of Environmental Approaches to Disease Prevention. New England Journal of Medicine, 367, 295-97. Doi: 10.1056/NEJMp1206268.

Collins, L.M., Chakraborty, B., Murphy, S.A., \& Strecher, V. (2009). Comparison of a phased experimental approach and a single randomized clinical trial for developing multicomponent behavioral interventions. Clinical Trials, 6, 5-15. Doi: 10.1177/1740774508100973.

Deci, E.L. \& Ryan, R.M. (2000). The "what" and the "why" of goal pursuits: Human needs and the self-determination of behavior. Psychological Inquiry, 11, 227-268.

Diabetes Prevention Program Research Group, Knowler WC, Fowler SE, Hamman RF, Christophi CA, Hoffman HJ, Brenneman AT, Brown-Friday JO, Goldberg R, Venditti E, Nathan DM. 
(2009). 10-year follow-up of diabetes incidence and weight loss in the Diabetes Prevention Program Outcomes Study. Lancet,, 374, 1677-1686. Doi: 10.1016/S0140-6736(09)61457-4.

Dombrowski, S.U., Avenell, A. \& Sniehotta, F.F. (2010). Behavioural interventions for obese adults with additional risk factors for morbidity: Systematic review of effects on behaviour, weight and disease risk factors. Obesity Facts, 3, 377-396. Doi: 10.1159/000323076.

Dombrowski, S.U., Knittle, K., Avenell, A., Araujo-Soares, V. \& Sniehotta, F.F. (2014). Long-term maintenance of weight loss in obese adults: A systematic review of randomised controlled trials of nonsurgical weight loss maintenance interventions with metaanalyses. British Medical Journal, 348:g2646 doi: 10.1136/bmj.g2646.

Epiphaniou E, \& Ogden J. (2010). Evaluating the Role of Life Events and Sustaining Conditions in Weight Loss Maintenance. Journal of Obesity. Doi.org/10.1155/2010/859413.

Jolly, K., Lewis, A., Beach, J., Denley, J., Peymane, A., Deeks, J.J., Daley, A., \& Aveyard, P. (2011). Comparison of range of commercial or primary care led weight reduction programmes with minimal intervention control for weight loss in obesity: Lighten Up randomised controlled trial. British Medical Journal, 343(7832):1035. Doi: 10.1136/bmj.d6500.

Hagger, M.S., Wood, C., Stiff, C. \& Chatzosarantis, N. L. (2010). Ego depletion and the strength model of self-control: a meta-analysis. Psychological Bulletin, 136, 495-525. Doi: 10.1037/a0019486.

Hardeman, W., Sutton, S, Griffin, S, Johnston, M, White, A, Wareham, N.J, \& Kinmonth, A.L. (2005). A causal modelling approach to the development of theory-based behaviour change programmes for trial evaluation. Health Education Research, 20, 676-687.

Jo, B., Asparouhov, T. \& Muthen, B. (2008). Intention-to-treat analysis in cluster randomised trials with non-compliance. Statistics in Medicine 27, 5565-5577. Doi: 10.1002/sim.3370. 
Larose J.G., Fava, J.L., Steeves, E.A., Hecht, J., Wing, R.R. \& Raynor, H.A. (2014). Daily selfweighing within a lifestyle intervention: Impact on disordered eating symptoms. Health Psychology, 33, 297-300. Doi: 10.1037/a0034218

Marlatt, G.A. \& W.H. George (1984). Relapse prevention - introduction and overview of the model. British Journal of Addiction, 79, 261-273.

Madigan, C.D., Aveyard, P., Jolly, K., Denley, J., Lewis, A. \& Danley, A.J. (in press). Regular selfweighing to promote weight maintenance after intentional weight loss: a quasi-randomized controlled trial. Journal of Public Health.

Perri, M.G., Nezu, A.M., McKelvey, W.F., Shermer, R.L., Renjilian, D.A. \& Viegener, B,J. (2001). Relapse prevention training and problem-solving therapy in the long-term management of obesity. Journal of Consulting and Clinical Psychology, 69, 722-726.

Penn, L., White, M., Lindström, J., den Boer, A.T., Blaak E, Eriksson, J.G., Feskens, E., IlanneParikka, P., Keinänen-Kiukaanniemi, S.M., Walker, M., Mathers, J., Uusitupa, M. \& Tuomilehto, J. (2013) Importance of Weight Loss Maintenance and Risk Prediction in the Prevention of Type 2 Diabetes: Analysis of European Diabetes Prevention Study RCT. PLoS ONE, 8(2): e57143. Doi: 10.1371/journal.pone.0057143.

Presseau, J., Sniehotta, F.F., Francis, J.J. \& Gebhardt, W.A. (2010). With a little help from my goals: integrating intergoal facilitation with the theory of planned behaviour to predict physical activity. British Journal of Health Psychology, 15, 905-919. Doi: 10.1348/135910710X494105.

Ross Middleton, K.M., Patidar, S.M. \& Perri, M.G. (2012). The impact of extended care on the longterm maintenance of weight loss: A systematic review and meta-analysis. Obesity Reviews, 13(6), 509-517. Doi: 10.1111/j.1467-789X.2011.00972.x.

Rothman, A.J. (2000). Toward a theory-based analysis of behavioral maintenance. Health Psychology, 19, 64-69. 
Simpson, S.A., Shaw, C. \& McNamara, R. (2012). What is the most effective way to maintain weight loss in adults? British Medical Journal, 344, 7838. Doi: 10.1136/bmj.d8042.

Strack, F. \& Deutsch, R. (2004). Reflective and impulsive determinants of social behavior. Personality and Social Psychology Review, 8, 220-247.

Wing, R.R., Tate, D.F., Gorin, A.A., Raynor, H.A. \& Fava, J.L. (2006). A self-regulation program for maintenance of weight loss. New England Journal of Medicine, 355, 1563-1571. 